\title{
Treatment of oral squamous cell carcinoma using anti-HER2 immunonanoshells
}

\author{
This article was published in the following Dove Press journal: \\ International Journal of Nanomedicine \\ 8 November 2011 \\ Number of times this article has been viewed
}

\section{Reza Fekrazad ${ }^{2}$ \\ Neda Hakimiha ${ }^{3}$ \\ Enice Farokhi ${ }^{3}$ \\ Mohammad Javad Rasaee ${ }^{4}$ \\ Mehdi Shafiee Ardestani ${ }^{5}$ \\ Katayoun AM Kalhori ${ }^{2}$ \\ Farzaneh Sheikholeslami' \\ 'Research \& Development \\ Department, Production and Research \\ Division of the Pasteur Institute of Iran, Karaj, Iran; ${ }^{2}$ Dental Department, AJA University of Medical Sciences, Laser Research Center, Dental Faculty, Tehran University of Medical Sciences; ${ }^{3}$ Dentistry Department, Faculty of Dentistry, Shahed University, Tehran, Iran; ${ }^{4}$ Department of Biotechnology, Faculty of Medical Sciences, Tarbiat Modares University, Tehran, Iran; ${ }^{5}$ Hepatitis and AIDS Department, Pasteur Institute of Iran, Tehran}

Correspondence: Farzaneh Sheikholeslami Research and Development Department, Production and Research Division, Pasteur Institute of Iran, Karaj, Iran Tel +98 26I 6100910 ext 665 Fax +98 26I 6l02900

Email farzane_sheikholeslami@yahoo.com
Background: Worldwide, oral squamous cell carcinoma (potentially mediated by HER2) is recognized as the most commonly occurring malignant neoplasm of the oral cavity. Anti-HER2 nanobodies conjugated to gold-silica nanoshells and used as photothermal treatment for oral squamous cell carcinoma may provide a novel therapeutic alternative to current treatment for this disease.

Methods: KB epithelial or HeLaS3 cell cultures (controls) were exposed to these immunonanoshells, and plasmon resonance electron initiation specific to gold was employed to burn the tumor cells.

Results: Following this treatment, significant cell death occurred in the KB tumor cell cultures while there was no evidence of cellular damage or death in the HeLaS3 cell cultures.

Conclusion: These findings suggest that photothermal treatment of oral squamous cell carcinoma has considerable advantages.

Keywords: anti-HER2 immunonanoshells, gold-silica nanoshells, photothermal treatment, oral squamous cell carcinoma

\section{Introduction}

Oral squamous cell carcinoma is histopathologically characterized by invasive islands of malignant squamous epithelial cells, and accounts for more than $90 \%$ of all malignant neoplasms of the oral cavity. The majority of these cancers are located on the tongue, mainly at the lateral posterior border. ${ }^{1,2}$ Current treatments are based on the clinical stage of the disease and may include surgical excision, radiation therapy, chemotherapy, or combination therapy, as well as new investigational methods such as immunotherapy or gene therapy. ${ }^{1,3,4}$ Surgical excision can result in complications, and the use of conventional radiotherapy may cause an oral cavity disorder, resulting in reduced patient survival time..$^{5}$ Because local carcinoma recurrences are common and current treatments can result in significant problems, alternative therapeutic approaches are warranted. ${ }^{6}$

Thermal therapy is emerging as a promising alternative strategy that is simple to perform and is advantageous as an alternative treatment for certain malignancies. The use of hyperthermia in the treatment of a variety of solid tumors has been under investigation for quite some time..$^{7-13}$

When generating nanoshells, it is possible to manipulate the size and layer of their composition and to conjugate antibodies with the nanoshells to target cancerous cells specifically. ${ }^{14-16}$ The nanoshells neither absorb nor scatter light emission, thereby 
allowing local destruction of tumor tissue. ${ }^{14,17,18}$ It is also possible to construct gold nanoshells that preferentially absorb light in the near infrared region of the spectrum (700-1100 nm) so that optical transmission through tissue is optimal. ${ }^{19}$ This property could be used for noninvasive excitation of nanoshells within tissue. Using antibody conjugation to target nanoparticle-encapsulated drugs to tumor sites has increasingly been incorporated as a therapeutic approach in cancer. ${ }^{20}$ A relatively high incidence of endothelial growth factor receptor and HER2 overexpression has been reported in oral squamous cell carcinoma. ${ }^{21-23}$

A previous study demonstrated that nanoshells injected into mice could accumulate at tumor sites because of the small size of the nanoparticles and enhanced permeability and retention effects. ${ }^{24}$ Following near-infrared laser irradiation to introduce cellular hyperthermia, tumors were completely eliminated. Neutron activation analysis has been used to detect and qualify gold (nanoshells) in blood, bone, and other tissues, and has been used to determine nanoshell concentrations in tumors. ${ }^{25}$ Further, the nanoshell is composed of substances (silica, gold, and targeting antibodies) that have also been used previously as nontoxic pharmacological agents. In this study, for the first time, the efficacy of photothermal treatment/near-infrared laser light with anti-HER2 nanobody-conjugated nanoshells was investigated in an in vitro model of oral squamous cell carcinoma.

\section{Materials and methods Cell lines and cell culture}

All cell lines were obtained from the cell bank at the Pasteur Institute of Iran. HER2-positive KB cells were grown in RPMI 1640 medium (Gibco-Invitrogen Corporation, Auckland, New Zealand). HER2-negative HeLaS3 cells were grown in HAM F12 medium (Gibco-Invitrogen Corporation). All media were supplemented with $10 \%$ fetal bovine serum and $1 \%$ antibiotics $(90 \mathrm{U} / \mathrm{mL}$ penicillin and $0.9 \mu \mathrm{g} /$ $\mathrm{mL}$ streptomycin). The cell cultures were maintained at $37^{\circ} \mathrm{C}$ in a humidified incubator under $5 \% \mathrm{CO}_{2}$.

\section{Gold-silica nanoshell fabrication}

The nanoshells were fabricated as previously described. ${ }^{26,27}$ All chemicals were purchased from Merck, Hohenbrunn, Germany. Three milliliters of $30 \%$ ammonia solution was mixed with $50 \mathrm{~mL}$ of absolute ethanol. After this, $1.5 \mathrm{~mL}$ of tetraethyl orthosilicate $6.7 \mathrm{mM}$ was added, and the solution was stirred overnight. The silica nanoparticles produced during this process were $100 \mathrm{~nm}$ in diameter. Treatment with organosilane produced surface-containing terminal amine groups. To make the nanoparticles functional, we mixed $50 \mu \mathrm{L}$ of $0.28 \mathrm{mM}$ organosilane with the silica nanoparticles. Following an overnight reaction, the solution was kept at a low boil for one hour to facilitate covalent bonding of organosilane to the surface of the silica nanoparticles. We then added dry ethanol gradually to maintain a constant volume. The solution was centrifuged at $2000 \mathrm{rpm}$ per minute at $4{ }^{\circ} \mathrm{C}$ for 30 minutes and redispersed in ethanol at least five times to remove excess materials.

For preparation of the gold nanoparticles, we rapidly mixed $45 \mathrm{~mL}$ of high-pressure liquid chromatography grade water with $0.5 \mathrm{~mL} \mathrm{NaOH}, 1 \mathrm{~mL}$ tetrakis (hydroxymethyl) phosphonium chloride and $1.5 \mathrm{~mL} \mathrm{HAuCL}_{4}$ into a $1 \% \mathrm{H}_{2} \mathrm{O}$ solution with vigorous stirring. The gold nanoparticles produced were approximately $3 \mathrm{~nm}$ in diameter, and were prepared as previously described by Duff et al and stored for two weeks at $6^{\circ} \mathrm{C} .{ }^{28}$ Following a 2-week incubation, $25 \mathrm{mg}$ of $\mathrm{K}_{2} \mathrm{CO}_{3}$ dissolved in $100 \mathrm{~mL}$ water was added, and $1.5 \mathrm{~mL}$ of $1 \% 2$-chloroauric acid was then vigorously mixed into the solution. Four milliliters of this solution was mixed with $100 \mathrm{~mL}$ of silica-gold nanoparticles. Finally, $10 \mu \mathrm{L}$ of $0.36 \mathrm{mM}$ formaldehyde was added, turning the solution dark blue. This solution was then centrifuged at $2000 \mathrm{rpm}$ per minute at $4^{\circ} \mathrm{C}$ for 30 minutes and redispersed in high-pressure liquid chromatography grade water at least twice to remove excess materials. The final estimation of the nanoshells was determined by optical absorption profiling using an ultraviolet-visible spectrophotometer (3100; Shimadzu, Tokyo, Japan). The dimensions of the nanoshells were assessed by electron microscopy (EM-900, 800 Kev; Zeiss, Oberkochen, Germany). The nanoshells used in this study were approximately $100 \mathrm{~nm}$ in diameter with a $10 \mathrm{~nm}$ thick gold shell and displayed an extinction peak at $820 \mathrm{~nm}$.

\section{Nanoshells anti-HER2 nanobody conjugation}

Approximately $8 \times 10^{8}$ nanoshells were suspended in a $\mathrm{K}_{2} \mathrm{CO}_{3}$ solution $(0.2 \mathrm{M}, \mathrm{pH} 8.2-8.8)$ at a final concentration of $8 \mu \mathrm{g} / \mathrm{mL}$ of SR-86 nanobody and then stirred gently using a stirrer magnet bar at room temperature. Next, $20 \mu \mathrm{L}$ of $1 \%$ polyethylene glycol (molecular weight 20,000) was added per $\mathrm{mL}$ of solution and stirred gently for 5 minutes at room temperature. A $20 \mu \mathrm{L}$ sample of $10 \%$ bovine serum albumin solution in phosphate-buffered saline ( $\mathrm{pH} 7.2-7.4$ ) was added for each milliliter of suspension and gently stirred for 5 minutes. The solution was poured into a tube (Sigma 3K30 Laborzentrifugen, Germany) and centrifuged 
at $14,000 \mathrm{~g}$ for 45 minutes at $4^{\circ} \mathrm{C}$ to remove excess reagents, such as unbound nanoshells or nanobodies. Following centrifugation, we removed $4.5 \mathrm{~mL}$ of supernatant and resolved the pellet in $20 \mu \mathrm{L}$ of $1 \%$ bovine serum albumin in phosphate-buffered saline ( $\mathrm{pH} 7.2-7.4)$ per $\mathrm{mL}$ of solution with gentle stirring for 5 minutes. The solution was then centrifuged at $14,000 \mathrm{~g}$ for 45 minutes at $4^{\circ} \mathrm{C}$. This step was then repeated, with the centrifugation step reduced to 30 minutes. The pellet was resuspended in $1 \%$ bovine serum albumin and stored at $4^{\circ} \mathrm{C}$.

\section{Molecular imaging of HER2 expression and in vitro photothermal therapy}

Cells were seeded onto 96 -well plates at a density of $5 \times 10^{3}$ cells $/ \mathrm{cm}^{2}$ and grown until nearly confluent. Images were taken with a Zeiss fluorescence microscope before and after laser irradiation. Cells were washed with phosphate-buffered saline twice, and $8 \times 10^{8}$ nanoshells $/ \mathrm{mL}$ were mixed with cell culture media without fetal bovine serum at an $8: 1$ ratio. The culture medium was removed from each well, and replaced with $100 \mu \mathrm{L}$ of the nanoshell solution. After one hour of incubation at $37^{\circ} \mathrm{C}$ under $5 \% \mathrm{CO}_{2}$, the cells were washed three times with phosphate-buffered saline to remove the unbound nanoshells. Next, a $4 \mathrm{~mm}$ diameter spot in each well was exposed to laser light (Med Art, Hvidovre, Denmark) at $820 \mathrm{~nm}$ and $4 \mathrm{~W} / \mathrm{cm}^{2}$ for two minutes. Eight hours later, the cells were examined using the MTT assay. ${ }^{29}$ A $50 \mu \mathrm{L}$ sample of MTT dye (Merck, $10 \mathrm{mg} / \mathrm{mL}$ in phosphatebuffered saline) was added to each well. The plates were incubated at $37^{\circ} \mathrm{C}$ for three hours and then centrifuged at $800 \mathrm{~g}$ for 10 minutes. Finally, the supernatant was aspirated. Formazan production was determined one hour after addition of $100 \mu \mathrm{L}$ of dimethyl sulfoxide (Merck) using an enzymelinked immunosorbent assay microplate reader (Labsystem, Multiskan MS, England) at $575 \mathrm{~nm}$.

\section{Results}

\section{Production of gold-silica nanoshells}

The gold-silica nanoshells were produced as previously described, and aliquots were conjugated to a targeting antibody. The extra sites on the nanoshells were blocked by adding a solution of bovine serum albumin. Figure 1 indicates that the absorption spectra of the bare nanoshells were nearly identical. The antibody did not have any detectable adsorption in the near-infrared region, indicating that the optical properties of the nanoshells must originate from the bare nanoshells. This finding suggests that the properties of the nanoshells were not altered by antibody conjugation or

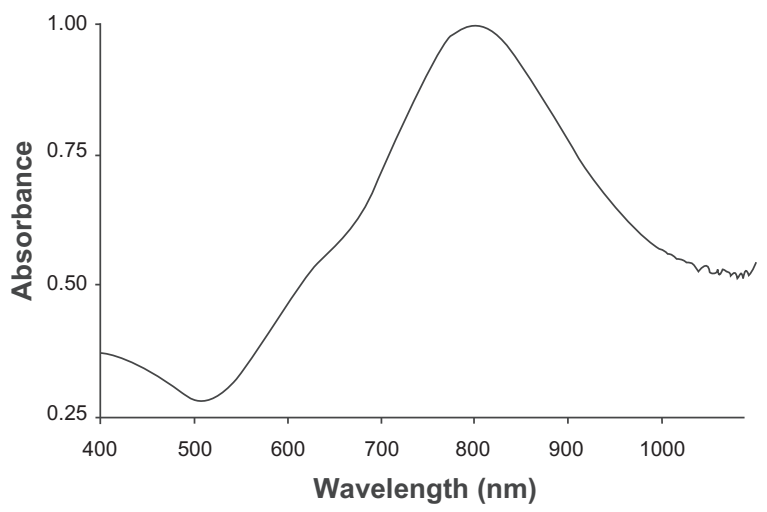

Figure I Spectral characteristics of near-infrared-absorbing nanoshells. The absorption spectrum shows the absorbing near-infrared nature $(820 \mathrm{~nm})$ of nanoshells with dimensions consisting of a silica core of $100 \mathrm{~nm}$ in diameter and shells approximately $10 \mathrm{~nm}$ thick. Predicted optical properties were confirmed using ultraviolet-visible spectrophotometry.

addition of bovine serum albumin. We visualized the goldsilica nanoshells using transmission electron microscopy (Figure 2).

\section{HER2-targeted nanoshells in KB and HeLaS3 cell lines}

As expected, bare nanoshells could be absorbed nonspecifically to the cell surface in both cell lines. Nonspecific attachment of the bare nanoshells could induce cell death in the area treated with laser, but cell mortality was low in the $\mathrm{KB}$ and HeLaS3 cells.

\section{HER2-targeted nanobody-conjugated nanoshells in KB and HeLaS3 cells}

The nanoshells conjugated to nanobodies were able to induce cell death effectively in KB cells overexpressing HER2 on their surface. The specificity and affinity of binding was

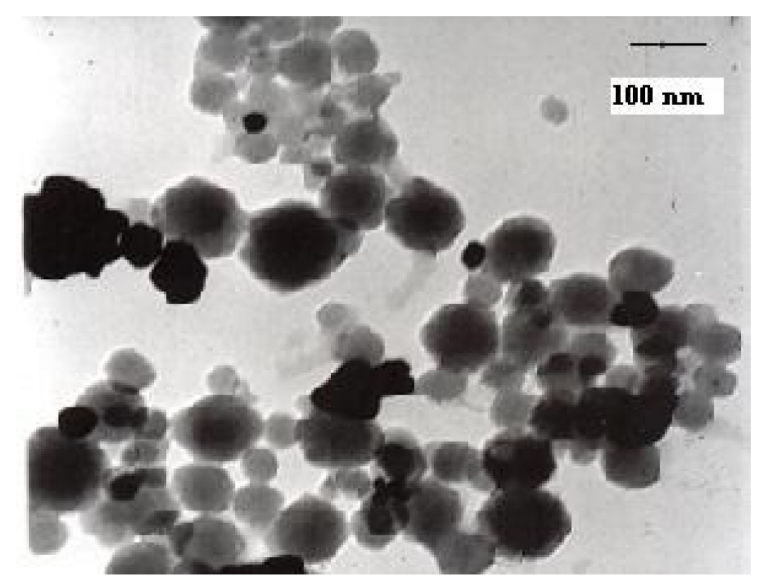

Figure 2 Transmission electron microscopic image of gold-silica nanoshells with an overall diameter of III $\pm 3 \mathrm{~nm}$.

Note: Scale bar $=100 \mathrm{~nm}$. 


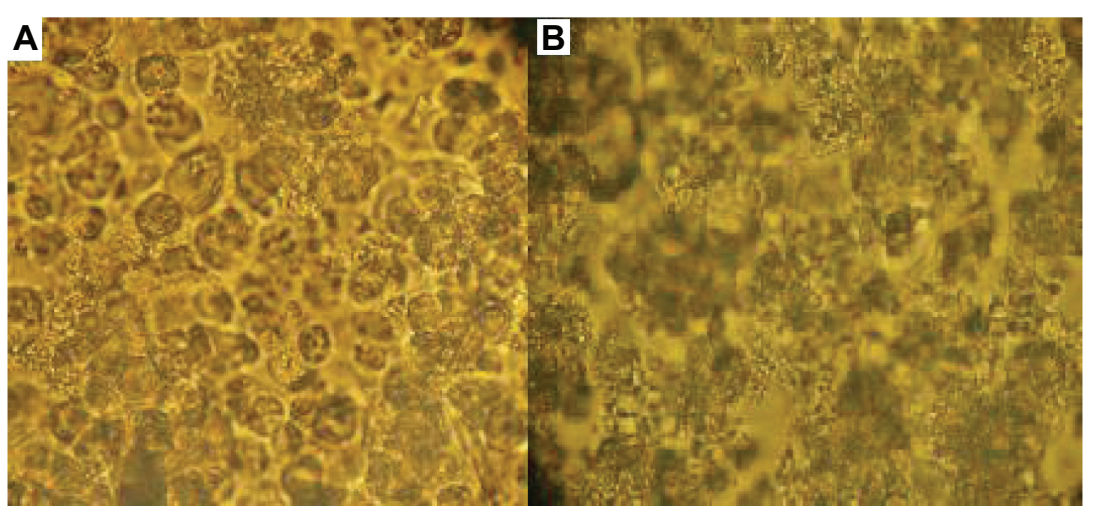

Figure 3 (A) HER2-positive KB cells exposed to anti-HER2 immunonanoshells (nanobody-conjugated nanoshells). (B) Cytotoxicity was observed in cells treated with nearinfrared laser. Images represent cells targeted with anti-HER2 nanoshells only.

confirmed previously by antibodies and antigen-based studies. ${ }^{22}$ A comparison of the images demonstrated the relationship between nanoshell absorption and cell cytotoxicity following laser treatment (Figure $3 \mathrm{~A}$ and $\mathrm{B}$ versus Figure 4A and B).

\section{Viability staining}

A cell viability staining experiment ${ }^{29}$ was performed in all the experimental groups. These assays were used to evaluate the number of living cells following near-infrared radiation. Each cell line was divided in four groups, and the viability of each group of cells was evaluated by the MTT assay (Figures 5-8). Nonspecific binding was responsible for $0.6 \%-$ $1.5 \%$ of cell death in KB cells while this number was slightly lower at $0.3 \%-0.9 \%$ in HeLaS3 cells (Figures 6 and 7). The highest mortality was observed in KB cells (69.4\%) following addition of the nanobody-nanoshell conjugates and subsequent exposure to laser radiation. Mortality was much lower in the HeLaS3 cells, at approximately 4\% (Figure 8). It should be noted that there was loss of both viable and dead cells due to reagent removal and washing during the experiment. It should be noted that there was a significant difference between all experimental groups.

\section{Discussion}

Improved therapies for oral squamous cell carcinoma, including surgery, chemotherapy, radiotherapy, and immunotherapy, are currently being evaluated to determine their efficacy in promoting long-term, disease-free survival. Photothermal therapy is a novel noninvasive treatment approach and is rapidly being recognized as one of the most effective therapeutic strategies for targeting tumor cells specifically.

In this study, anti-HER2 nanobody-tagged gold-silica nanoshells were generated, and their photothermal potency was examined in $\mathrm{KB}$ and $\mathrm{HeLaS} 3$ cells. Our data demonstrated selective tumor destruction of more than $69.4 \%$ of KB (HER2positive) cells with no mortality in HeLaS3 (HER2-negative) cells. It should be noted that nonspecific binding of conjugated nanoshells and extra reagents was minimized by washing to prevent cell death following near-infrared laser radiation.

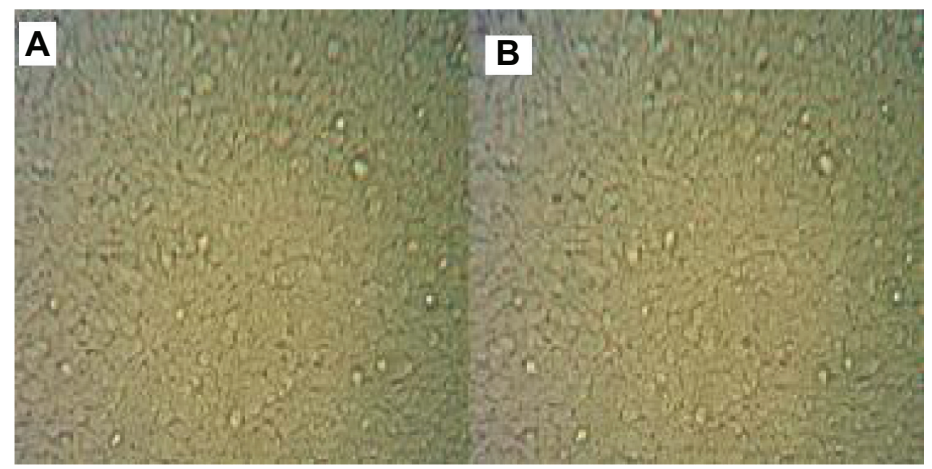

Figure 4 (A) HER2-negative HeLaS3 cells treated with anti-HER2 immunonanoshells. (B) No cytotoxicity was observed in HeLaS3 cells following near-infrared laser treatment. 


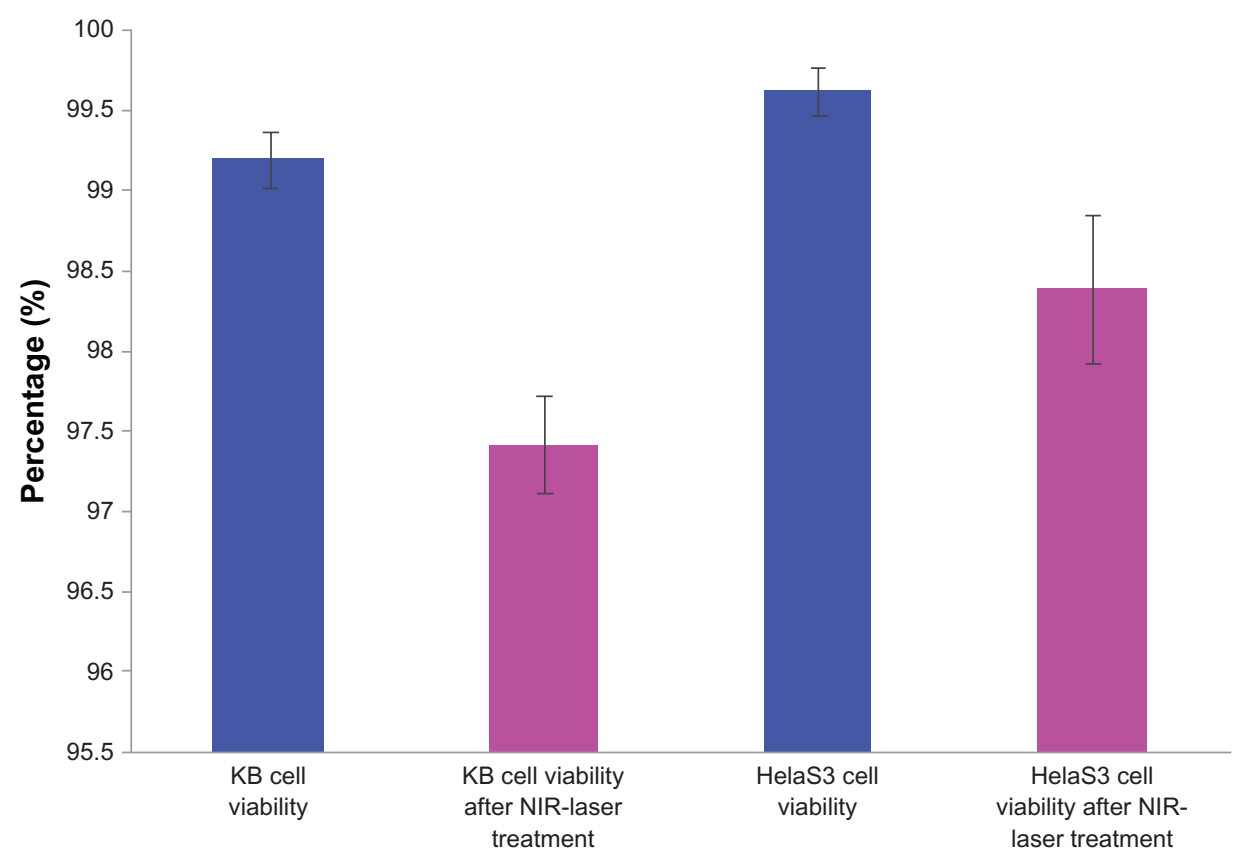

Figure 5 MTT assay results for normal HER2-positive (KB) and HER2-negative (HeLaS3) cells before and after near-infrared laser irradiation. Abbreviation: NIR, near-infrared.

Our current data highlight several advantages of nanobody-conjugated nanoshells compared with current treatments for oral squamous cell carcinoma. Nanobody labeling of nanoshells serves to increase nanoparticle specificity and therapeutic efficiency in vitro and is rapidly emerging as a new therapeutic class of immunonanoshells. For use in vivo, increasing nanoparticle specificity would be beneficial in that it would result in a higher accumulation of nanoparticles in the target tissue. It should be noted that there is no resistance to photothermal application

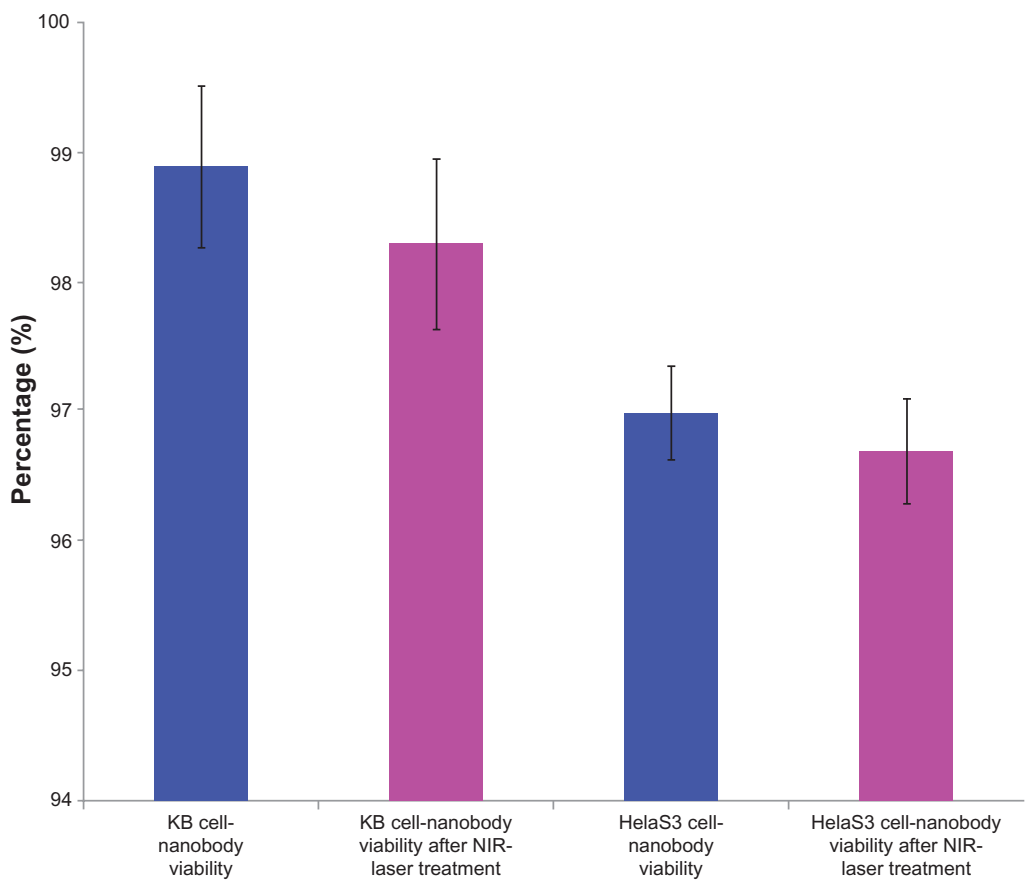

Figure 6 MTT assay results for KB and HeLaS3 cells following treatment with HER2-targeted nanobodies and near-infrared laser. Abbreviation: NIR, near-infrared. 


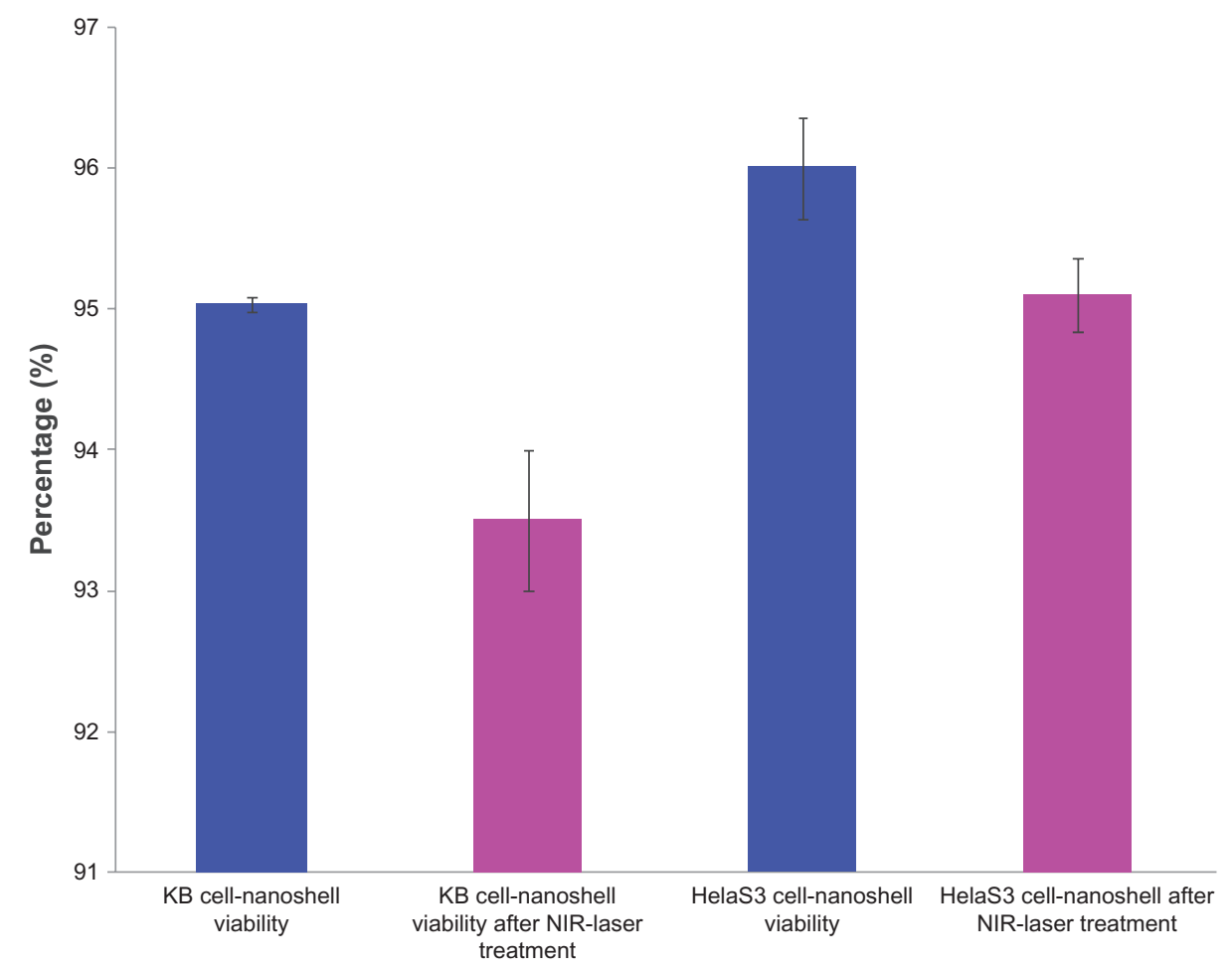

Figure 7 MTT assay results for KB and HeLaS3 cells exposed to bare nanoshells. Both cell types were treated with a near-infrared laser. Abbreviation: NIR, near-infrared.

for use in vivo. It has been observed that current tumor therapies can induce cancer cells to alter their cell surface marker expression; however, nanoparticles could localize to target cancer cells without causing any detectable cellular alterations. Furthermore, our toxicology results indicate that the anticancer effects of our immunonanoconjugate are limited to the areas exposed to near-infrared laser irradiation. The requirement for the presence of both nanoshells and laser light to induce cell death is promising for use in tumors in which local recurrence is often the most serious risk and the surrounding normal tissues perform critical functions. In conclusion, we demonstrate for the first time

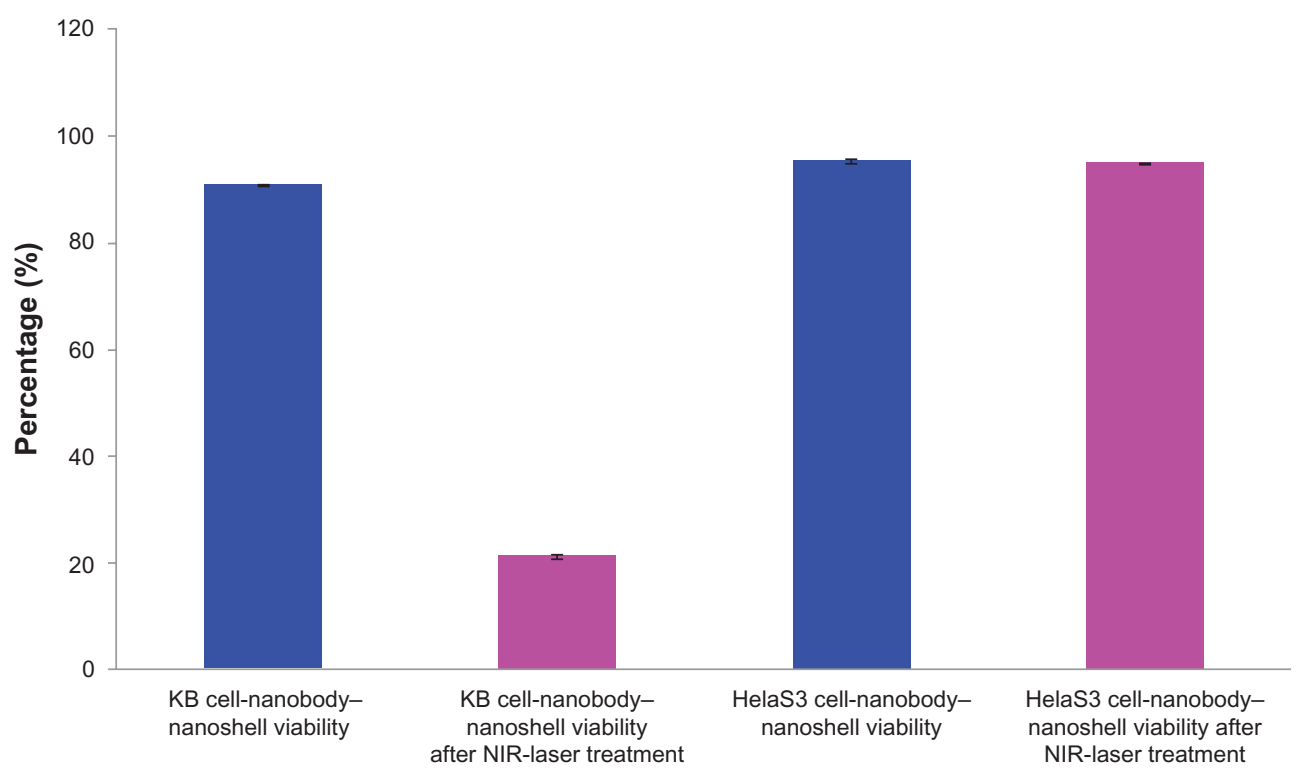

Figure 8 Anti-HER2 immunonanoshells (nanobody-conjugated nanoshells) were added to KB and HeLaS3 cells, and the cells were treated with an near-infrared laser. An MTT assay was performed on both cell types and our results indicated that immunotargeted nanoshells can selectively induce specific cell death in vitro. Abbreviation: NIR, near-infrared. 
that immunonanoshells containing nanobody conjugates can be used to induce selective cancer cell death in vitro. In vivo studies are currently underway in mouse models of oral squamous cell carcinoma to determine the therapeutic efficacy of gold-silica nanobody immunonanoshells.

\section{Acknowledgment}

We thank the staff of the Biotechnology Department of Medical Sciences, Tarbiat Modares University, for their technical assistance with this research.

\section{Disclosure}

The authors report no conflicts of interest in this work.

\section{References}

1. Neville BW, Damm DD, Allen CM, et al. Oral and Maxillofacial Pathology. 3rd ed. St Louis, MO: Saunders; 2009:365-370.

2. Hirota SK, Migliari DA, Sugaya NN. Oral squamous cell carcinoma in a young patient Case report and literature review. A Bras Dermatol. 2006;81(3):251-254.

3. Spencer KR, Ferguson JW, Wiesenfeld D. Current concepts in the management of oral squamous cell carcinoma. Aust Dent J. 2002;47(4): 284-289.

4. Méndez E, Cheng C, Farwell DG, et al. Transcriptional expression profiles of oral squamous cell carcinomas. Cancer. 2002;95(7):1482-1494.

5. Yao M, Chang K, Funk GF, et al. The failure patterns of oral cavity squamous cell carcinoma after intensity-modulated radiotherapy - the University of Iowa experience. Int J Radiat Oncol Biol Phys. 2007; 67(5):1332-1341.

6. Roberg K, Jonsson AC, Grenman R, Norberg-Spaak L. Radiotherapy responses in oral squamous carcinoma cell lines: evaluation of apoptotic proteins as prognostic factors. Head Neck. 2007;29(4):325-334.

7. O’Neal DP, Hirsch LR, Halas NJ, Payne JD, West JL. Photo-thermal tumor ablation in mice using near infrared-absorbing nanoparticles. Cancer Lett. 2004;209(2):171-176.

8. Philipp CM, Rohde E, Berlien HP. Nd:YAG laser procedures in tumor treatment. Semin Surg Oncol. 1995;11(4):290-298.

9. Prudhomme M, Tang J, Rouy S, et al. Interstitial diode laser hyperthermia in the treatment of subcutaneous tumor. Lasers Surg Med. 1996;19(4):445-450.

10. Chen WR, Adams RL, Higgins AK, Bartels KE, Nordquist RE. Photothermal effects on murine mammary tumors using indocyanine green and an $808 \mathrm{~nm}$ diode laser: an in vivo efficacy study. Cancer Lett. 1996; 98(2):169-173.

11. Jolesz FA, Hynen K. Magnetic resonance image-guided focused ultrasound surgery. Cancer J. 2002;8 Suppl 1:S100-S112.
12. Gazelle GS, Goldberg SN, Solbiati L, Livraghi T. Tumor ablation with radio-frequency energy. Radiology. 2000;217(3):633-646.

13. Hirsch LR, Gobin AM, Lowery AR, et al. Metal nanoshells. Ann Biomed Eng. 2006;34(1):15-22.

14. Lowery AR, Gobin AM, Day ES, Halas NJ, West JL. Immunonanoshells for targeted photothermal ablation of tumor cells. Int J Nanomedicine. 2006;1(2):149-154.

15. Wu X, Liu H, Liu J, et al. Immunofluorescent labeling of cancer marker HER-2 and other cellular targets with semiconductor quantum dots. Nat Biotechnol. 2003;21(1):41-46.

16. Verel I, Heider KH, Siegmund M, et al. Tumor targeting properties of monoclonal antibodies with different affinity for target antigen CD44V6 in nude mice bearing head and neck cancer xenografts. Int J Cancer. 2002;99(3):396-402.

17. Bernardi RJ, Lowery AR, Thompson PA, Blaney SM, West JL. Immunonanoshells for targeted photothermal ablation in medulloblastoma and glioma: an in vitro evaluation using human cell lines. J Neurooncol. 2008;86(2):165-172.

18. Hirsch LR, Stafford RJ, Bankson JA, et al. Nanoshell-mediated near infrared thermal therapy of tumors under magnetic resonance guidance. Proc Natl Acad Sci U S A. 2003;100(23):13549-13554.

19. Weissleder R. A clearer vision for in vivo imaging. Nature Biotechnol. 2001;19(4):316 -317.

20. Reynolds AR, Moghimi SM, Hodivala-Dilke K. Nanoparticle mediated gene delivery to tumor neovasculature. Trend Mol Med. 2003; 9(1):2-4.

21. Xia W, Lau YK, Zhang HZ, et al. Combination of EGFR, HER-2/neu, and HER-3 are a stronger predictor for the outcome of oral squamous cell carcinoma than any individual family members. Clin Cancer Res. 1999;5(12):4164-4174.

22. Sheikholeslami F, Rasaee MJ, Shokrgozar MA, et al. Isolation of a novel nanobody against HER2/neu using phage display technology. LabMedicine. 2010;41(2):69-75.

23. Bernarde VF, Gleber-Netto FO, Sousa SF, Silva TA, Aguiar MC. Clinical significance of EGFR, Her-2 and EGF in oral squamous cell carcinoma: a case control study. Exp Clin Cancer Res. 2010;29(1):40.

24. Maeda H, Fang J, Inutsuka T, Kitamoto Y. Vascular permeability enhancement in solid tumor: various factors, mechanisms involved and its implications. Int Immunopharmacol. 2003;3(3):319-328.

25. James WD, Hirsch LR, West JL, O’Neal PD, Payne JD. Application of INAA to the build-up and clearance of gold nanoshells in clinical studies in mice. JRNC. 2007;271(2):455-459.

26. Oldenburg SJ, Averitt RD, Westcott SL, Halas NJ. Nanoengineering of optical resonances. Chem Phys Lett. 1998;288(2-4):243-247.

27. Stöber W, Fink A, Bohn E. Controlled growth of monodisperse silica spheres in the micron size range. J Colloid Interface Sci. 1968; 26:62-69.

28. Duff DG, Baiker A, Edwards P. A new hydrosol of gold clusters. 1 Formation and Particle size variation. Langmuir. 1993;9:2301-2309.

29. Mosmann T. Rapid colorimetric assay for cellular growth and survival: application to proliferation and cytotoxicity assays. J Immunol Methods. 1983;65(1-2):6-24.
International Journal of Nanomedicine

\section{Publish your work in this journal}

The International Journal of Nanomedicine is an international, peerreviewed journal focusing on the application of nanotechnology in diagnostics, therapeutics, and drug delivery systems throughout the biomedical field. This journal is indexed on PubMed Central, MedLine, CAS, SciSearch $₫$, Current Contents ${ }^{\circledR} /$ Clinical Medicine,

\section{Dovepress}

Journal Citation Reports/Science Edition, EMBase, Scopus and the Elsevier Bibliographic databases. The manuscript management system is completely online and includes a very quick and fair peer-review system, which is all easy to use. Visit http://www.dovepress.com/ testimonials.php to read real quotes from published authors. 